\title{
LINKING DEMOGRAPHY TO THE PERCEPTION OF (UN)SUSTAINABILITY
}

\author{
Vanya Kraleva ${ }^{152}$ \\ Svilen Ivanov ${ }^{153}$
}

https://doi.org/10.31410/itema.2018.375

\begin{abstract}
In recent years, the issues of sustainable development and how to achieve it are widely discussed in the scientific literature. At the same time, there is a lack of consensus at all levels of what sustainable development means and whose responsibility it is. If at the institutional level this issue seems to be well defined, the perception of the individual about the concept of sustainability and the associated roles is poorly explored. In this paper it is argued that people have different understanding of sustainability drivers and their importance which is combined with their individual perception of how effectively problems are solved forms a gap of unsustainability. This gap in citizens' assessments can be seen as a motivating factor for their sustainable behavior.

Based on an empirical study this report aims at linking the demographic profile of respondents to their individual perception of unsustainability by analyzing the mismatch between the ideal view of sustainable development and its perceived current state. In order to measure this gap there is developed a measurement scale. The research builds on a survey with a sample of 200 participants from Bulgaria.

The data obtained are analyzed through descriptive statistical methods, correlation analysis and nonparametric tests. Characteristics such as gender, age, place of residence, social status, and forms of engagement with solving social and environmental problems are investigated. On the basis of the analysis there are defined specific areas where this gap is significant.

The results of the study can be used in profiling the segment of active people sensitive to the problems of sustainability. The constructed measurement scale can be used in further research of the role that the gap observed between the ideal view and the perceived reality might have as a trigger for sustainable behaviour.
\end{abstract}

Keywords: sustainable development, perception of unsustainability, demographic profile, activism, sustainable behaviour, motivation

\section{INTRODUCTION}

ince 1987 when the World Commission on Environment and Development (WCED) released its report „Our common future“, there started a discussion on the necessity to $\checkmark$ develop in a way that meets the needs of the present without compromising the ability of future generations to meet their own needs[1]. As identified by the Commission there are three main pillars which should be kept in balance if a sustainable development is to be achieved: economic growth, environmental protection and social equality. About 30 years later following a vivid political and scientific discussion, in 2015 the world community has reaffirmed its commitment to sustainable development by endorsing Agenda 2030 and its 17 goals [2]. The understanding of this multi-faced concept adopted in the Agenda broadens its scope to

${ }^{152}$ University of Economics - Varna, 77 Knyaz Boris I Blvd., Varna, Bulgaria
${ }^{153}$ University of Economics - Varna, 77 Knyaz Boris I Blvd., Varna, Bulgaria 
encompass the 5 Ps of sustainable development: people, planet, prosperity, peace and partnership.

With this act the world community focuses not on the separate players of sustainable development - institutions, business and society - but emphasizes the need to build partnership between them. In this context the inclusion of the individual in the processes related to the fulfillment of the 17 goals is a must, because only humans can build and grow relationships. It is uncommon, however, to expect that everyone would recognize each of these sustainability goals as their own. On the contrary, it is much more realistic to try to identify a set of objectives that are relevant to a particular segment and motivate these individuals to act in that specific area.

To date, the research on the relation between sustainable behaviour and demographic characteristics of the individual such as gender, age, education, activism, donations, etc. is well covered in the scientific literature. A common problem of most studies, however, is that they consider only isolated parts of behavior, such as sustainable consumption [3] - [8], recycling [9] - [11], energy conservation [12], [13], etc. This makes reason to say then that the interest is mainly on separate types of behaviour analyzed in detail, without giving an idea of the whole picture of sustainable behaviour. Through this paper the focus is on the broader scope of sustainable behaviour.

In marketing literature the rationale behind sustainable behaviour is discussed mainly from a socio-psychological perspective with regard to the underlying internal and external factors such as values, beliefs, social pressure, abilities and constraints, etc. Among the theories used to conceptualize the antecedents of sustainable behaviour are the Norm Activation Theory of Altruism [14], the Theory of Planned Behaviour [15], the Value-Belief-Norm Theory of Environmentalism [16], and the Model of Sustainable Action [17] where a key construct is the gap between the ideal view of sustainable development and its perceived current state (GIVPR). Pointing on this key construct this paper speculates that the notion of sustainable development and respectively the assessment of whether it is achieved or not might differ across people. At the same time, examining the relationship between demographic characteristics and the importance that people pay to different sustainability factors, would allow for the profiling of user segments characterized by varying degrees of sensitivity to the different dimensions of sustainable development. Thus we aim at linking the demographic profile of respondents to their individual perception of the scale of unsustainability. It is argued that the gap between the ideal view of the world and its perceived current state is a key construct that can give a better understanding of the drivers of sustainable action. The research aim is achieved through an online survey among target audience to analyze the mismatch between the ideal view of sustainable development and its perceived current state and profiling of respondents regarding their perception of the unsustainability gap.

\section{METHODOLOGY}

In this paper we regard the perception of unsustainability as the mismatch between the ideal view of sustainable development and its perceived current state. In order to measure the perception of unsustainability and link it to demography we use the GIVPR scale developed in [17]. The instrument used consists of three dual scales that focus on the intersections between the three dimensions of sustainable development: economic growth, environmental protection and social equality. This forms three zones of sustainability which are socio-economic equity, resources viability and bearable living conditions. Resonating the adopted in Agenda 2030 [2] 
broader understanding of the sustainability concept, the variables in these three zones encompass each of the 5 Ps of sustainable development: people, planet, prosperity, peace and partnership. The total number of items of the scale is 46 for measuring the ideal view of the world and another 46 reflecting the perceived reality. Analyzing the collected data we compute a set of 46 new variables which describe the gap between the ideal view of sustainable development and its perceived current state. In order to stress on the existing problems we transform their meaning to have a negative connotation. On this basis we test the relationships between demography and the perception of this gap. To select the demographic characteristics related to sustainable behaviour we use previous research [6], [9] - [11].

The data is collected in the period February-March 2018 using an online survey among Bulgarian population. The total sample of the survey is 200 respondents. Their profile includes $59 \%$ males and $41 \%$ females. The share of respondents bellow 25 years of age is $39 \%$ and those above 56 are $8 \%$. Only $28 \%$ of them have children. There is a nearly equal distribution of educational groups - 31,7\% have Secondary or lower education, 31,6\% have Bachelor degree and $36,7 \%$ - Master or higher. The majority of respondents live in cities $(94,5 \%, 12 \%$ of them reside in the capital city of Bulgaria). Regarding active citizenship 35\% declare to have made at least one donation in the last three years, $54,5 \%$ to have volunteered and $21,5 \%$ to have participated in a form of protest during the same period.

\section{RESULTS AND DISCUSSION}

The computed variables describing the gap between the ideal view of sustainable development and its perceived current state show the most problematic areas. According to respondents these are the inefficiency of the Juridical system, the unproductive actions in support of socially disadvantaged groups and the insufficient investments for environmental protection and its monitoring. Figure 1 gives an inside of the scope that the gap between the ideal view and its perceived current state have reached for the five less and for the five most problematic areas. A gap of 5.56 which is computed for the ineffectiveness of the Juridical system, for example, means that for most people it is extremely important for this system to be effective (which is rated with an average of 6,46 out of 7), but their perception is that currently it is not achieved at all (which is rated with an average of only 2,12 out of 7).

Figure 1: The Scope of Unsustainability

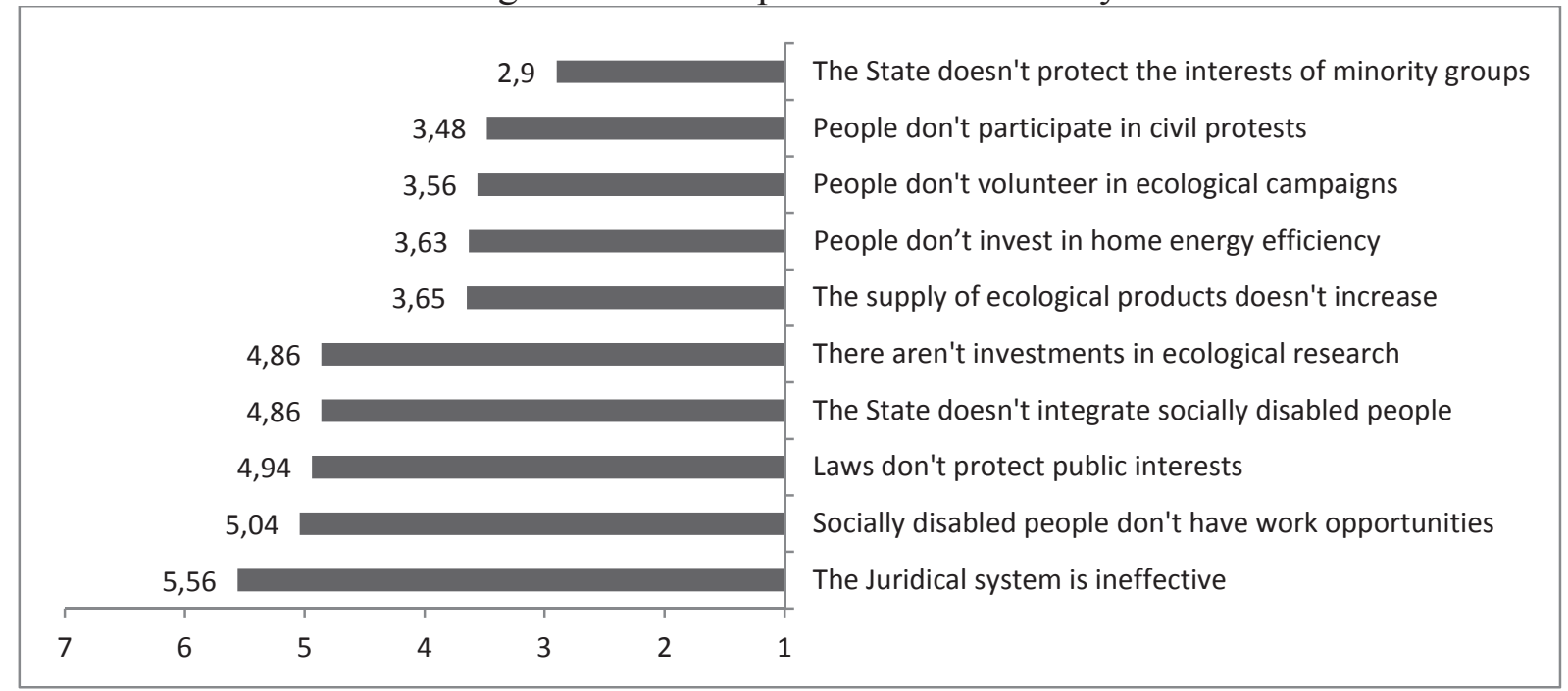


On the other side of the continuum we find the statement that the State does/doesn't protect the interests of minority groups where the gap seems to be only 2,9 out ot 7 . It is worth mentioning though that according to more than $32 \%$ of respondents this gap is even negative, i.e. they think that the State is overprotecting minorities and it can't be part of the sustainable development idea. For the rest of the statements the negative gap varies to up to $6 \%$ of respondents and proves to be more significant regarding the social direction of taxation policy, the manifestation of tolerance among people and the transparency of businesses (Figure 2).

Figure 2: The Perception of Overachievement

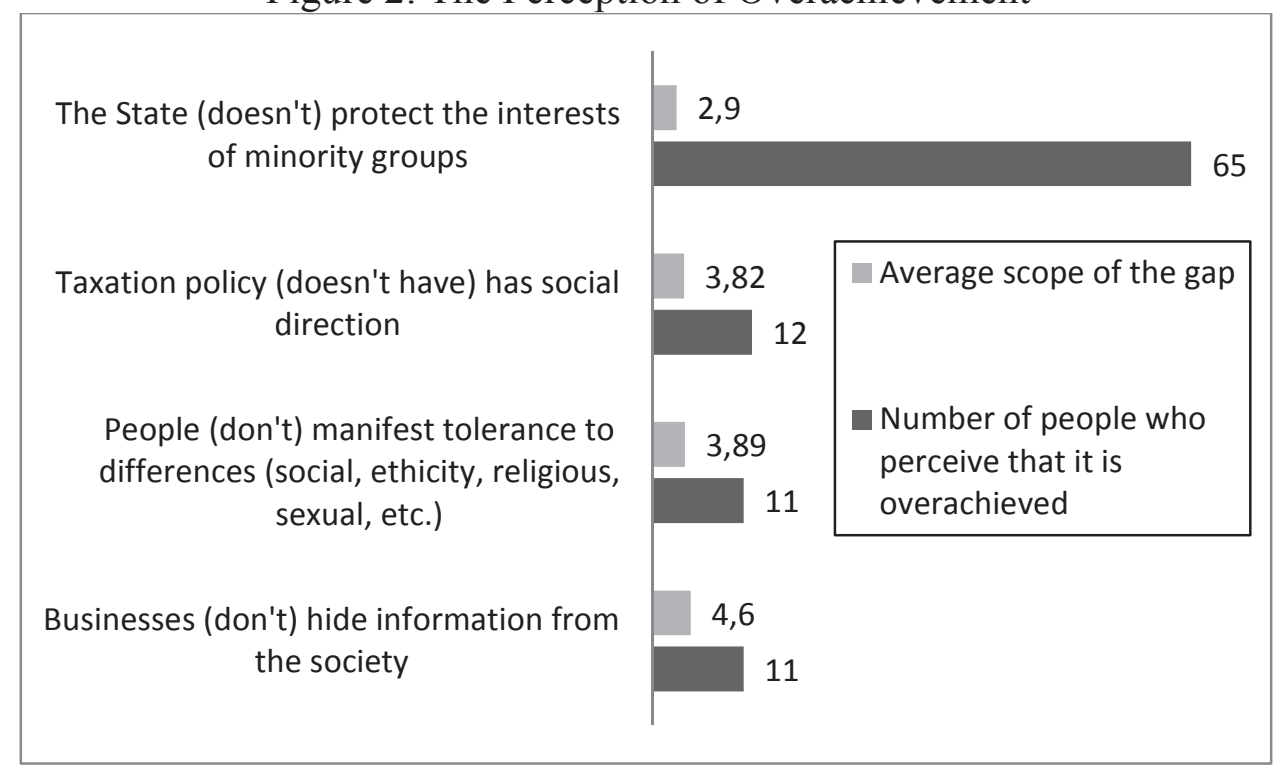

This discrepancy can be interpreted as directly related to the specifics of the integration policies (formal and informal) of minority groups in Bulgaria and the ways in which they are understood. In Bulgaria there exist strongly rooted racial and religious stereotypes, which explain the significant spatial, labor and educational distances maintained towards a large part of ethnic minorities and potential immigrant communities [18]. According to the last census in 2011 minority groups in Bulgaria constitute about 14,4\% of the population, where the biggest groups are the Turks $(8,5 \%)$ and Roma (4,9\%) [19]. Although many actions for minority integration are undertaken, it is difficult to find any significant results. The level of education and inclusion in social life of minorities is low and their access to the labor market is limited. The minority on focus is the Roma group. Statistics show that only $23 \%$ of its members are employed and about 65\% of young Roma aged 16-24 are neither in employment nor in education and training [20]. Many members of these groups live in closed areas in major cities, mostly relying on social assistance, and the level of domestic crime is high. This gives rise to public intolerance, often expressed in support of extreme ideas, mostly related to the desire for segregation. In this sense, the notion that the state is doing more than the necessary can be interpreted as a manifestation of a negative attitude towards the idea of how realistic the integration of minority groups in Bulgaria is. It can also be argued that it influences the emergence of a "negative" gap regarding the social direction of taxation policy and the manifestation of (in)tolerance to social, ethnic, etc. differences.

Specifics related to the social and cultural situation in Bulgaria can also be found for the rest 4 "less problematic" areas (Figure 1). In recent years, more and more citizens, mostly from large cities and the capital, have been involved in protests against the government or against changes in laws that are suspected of protecting the interest of private companies. On the other hand, 
Bulgaria ranks on the unenviable 111 place in the World Press Freedom Index, and many national media always occupy a pro-governmental position. As a result of the spread of distorted information about protest actions through the media, society is divided into two opposing positions, because people living in small settlements have no access to objective information. It is likely that this fact explains the small gap on the statement "People don't participate in civil protests".

In interpreting the assessments of respondents' opinions on the role of investments in domestic energy efficiency, there should be mentioned the propensity of Bulgarian households, mostly from small settlements, to use solid fuel for heating due to the constrained access to alternative energy sources. In this sense, the assessments here may be dependent on the lack of opportunity for investment in energy efficiency of households.

In order to test the relationship between demographic characteristics and the perception of unsustainability a correlation analysis is performed. Each of the ten demographic characteristics is crossed with all of the variables describing the gap between the ideal view and the perception of reality. These variables are grouped in three zones of sustainability as defined in [17]: socioeconomic equity, resources viability and bearable living conditions. The analysis shows that there are a total of 85 statistically significant relations between the demographic characteristics and the perception of unsustainability (Table 1).

Table 1: Linking Demography to the Perception of Unsustainability

\begin{tabular}{|c|c|c|c|c|}
\hline \multirow{3}{*}{ Demography } & \multicolumn{4}{|c|}{ Number of statistically significant relations found } \\
\hline & $\begin{array}{l}\text { Socio-economic } \\
\text { equity }\end{array}$ & Resources viability & $\begin{array}{c}\text { Bearable living } \\
\text { conditions }\end{array}$ & Total \\
\hline & (out of 15 variables) & (out of 15 variables) & (out of 16 variables) & (out of 46 variables) \\
\hline Gender & 2 & 5 & 14 & 21 \\
\hline Education & 1 & 1 & 0 & 2 \\
\hline Place of residence & 2 & 1 & 1 & 4 \\
\hline Age & 4 & 3 & 4 & 11 \\
\hline Parentship & 7 & 2 & 3 & 12 \\
\hline Volunteering experience & 6 & 7 & 3 & 16 \\
\hline Participation in protests & 1 & 1 & 1 & 3 \\
\hline Donations to NGOs & 0 & 0 & 1 & 1 \\
\hline Satisfaction with personal income & 8 & 1 & 6 & 15 \\
\hline Sensitivity to social problems & 0 & 0 & 0 & 0 \\
\hline Total & 31 & 21 & 33 & 85 \\
\hline
\end{tabular}

Within the first zone the characteristics that influence the most the perception of socioeconomic equity are parentship, volunteering experience and satisfaction with personal income. Gender and volunteering experience determine the assessment of resources viability. Within the third zone most influential turn to be again gender and the satisfaction with personal income. Based on this analysis there can be defined 5 demographic characteristics that correlate with the perception of unsustainability more often than others and these are: gender, age, parentship, volunteering experience and satisfaction with personal income. The empirical data also proves that the sensitivity to social problems has no influence on the perceived gap between the ideal view and the perception of reality. For the rest of the demographic variables there are found from 1 to 4 correlations.

These results prove for the link between demography and the perception of unsustainability and can be used in profiling the segment of active people sensitive to these problems. In further 
research it must be taken into account, however, that the demographic profile of Bulgarians might differ from other nations in terms of income and social activism. The interpretation of the results shown in Table 1 suggest that due to the specificity of its cultural, social, media and political environment, Bulgarian society is divided in terms of interpretation of several key topics. These include minority policies, participation in civil protests and environmental initiatives. This does not mean that these three variables need to be removed from the research tool in later studies for not being related to the perception of unsustainability. However, a recommendation may be made in future studies to take into account the specificities of external influences that directly affect these perceptions.

\section{REFERENCES}

[1] WCED (1987). Our Common Future: Report of the World Commission on Environment and Development.

[2] United Nations (2015). Transforming our World: The 2030 Agenda for Sustainable Development. A/Res/70/1.

[3] Kinnear, T. C., Taylor, J. R., \& Ahmed, S. A. (1974). Ecologically Concerned Consumers: Who Are They? // Journal of Marketing, 38(2), 20-24.

[4] Paço, A., \& Raposo, M. (2009). "Green” segmentation: An application to the Portuguese consumer market. // Marketing Intelligence and Planning.

[5] Kaufmann, H.R., Ali Khan Panni, M.F., Orphanidou, Y. (2012). Factors Affecting Consumers' Green Purchasing Behavior: An Integrated Conceptual Framework // The Amfiteatru Economic Journal, Academy of Economic Studies - Bucharest, Romania, vol. 14(31), pages 50-69, February.

[6] Mohr, M., \& Schlich, M. (2016). Socio-demographic basic factors of German customers as predictors for sustainable consumerism regarding foodstuffs and meat products // International Journal of Consumer Studies.

[7] Bulut, Z. A., Cimrin, F. K., \& Doagn, O. (2017). Gender, generation and sustainable consumption: Exploring the behaviour of consumers from Izmir, Turkey // International Journal of Consumer Studies, 41(6), 597-604.

[8] Joshi, Y., \& Rahman, Z. (2017). Investigating the determinants of consumers' sustainable purchase behaviour // Sustainable Production and Consumption, 10, 110-120.

[9] Schultz, P. W., Oskamp, S., \& Mainieri, T. (1995). Who recycles and when? A review of personal and situational factors // Journal of Environmental Psychology, 15(2), 105-121

[10] Swami, V., Chamorro-Premuzic, T., Snelgar, R., \& Furnham, A. (2011). Personality, individual differences, and demographic antecedents of self-reported household waste management behaviours // Journal of Environmental Psychology, 31(1), 21-26.

[11] Seacat, J. D., \& Boileau, N. (2018). Demographic and community-level predictors of recycling behavior: A statewide, assessment // Journal of Environmental Psychology, 56, $12-19$.

[12] Abrahamse, W., \& Steg, L. (2009). How do socio-demographic and psychological factors relate to households' direct and indirect energy use and savings? // Journal of Economic Psychology, 30(5), 711-720.

[13] Gaspar, R., Antunes, D., Faria, A., \& Meiszner, A. (2017). Sufficiency before efficiency: Consumers ' profiling and barriers/facilitators of energy efficient behaviours // Journal of Cleaner Production, 165, 134-142.

[14] Schwartz, S. H. (1977) Normative Influences on Altruism // Advances in Experimental Social Psychology (Vol. 10, pp. 221-279): Academic Press. 
[15] Ajzen, I. (1985) From Intentions to Actions: A Theory of Planned Behavior. In J. Kuhl \& J. Beckmann (Eds.), Action Control: From Cognition to Behavior (pp. 11-39). Berlin, Heidelberg: Springer Berlin Heidelberg.

[16] Stern, P. C. 2000. Toward a Coherent Theory of Environmentally Significant Behavior // Journal of Social Issues, 56(3), 407-424.

[17] Kraleva, V. \& Ivanov, S. (2018) Towards a General Model of Sustainable Involvement // Proceedings of the $10^{\text {th }}$ International Scientific Conference "New Challenges of Economic and Business Development - 2018: Productivity and Economic Growth", 10-12 May 2018, Riga, University of Latvia.

[18] Pamporov, A. (2009) Social Distances and Ethnic Stereotypes of Minority Groups in Bulgaria. Sofia: Open Society Institute.

[19] National Statistical Institute (NSI). 2011 Census.

[20] European Union Agency for Fundamental Rights (2016) Second European Union Minorities and Discrimination Survey (EU-MIDIS II) Roma: Selected Findings. Luxembourg: Publications Office of the European Union. 